\title{
Blok A, Farías I \& Roberts C (eds) (2020) The Routledge Companion to Actor- Network Theory. London: Routledge. 458 pages. ISBN: 9781315111667
}

\author{
Helen Verran \\ Helen.Verran@cdu.edu.au
}

True to its title, this Companion to Actor-Network Theory encourages readers to take up ANT as companion in their inquiries; it urges scholars to come along on a common adventure. And indeed, the ANT, or more properly the ANT family, proposed here, is an eminently companionable one, a contrast to some of the rather all-or-nothing ways ANT has been characterised in the past. In the introduction, the editors stress ANT as "an intellectual practice" (p. xxiv) expressed in diverse methods which nevertheless bear family resemblances. A reader gathers that to be accepted as an ANT scholar is merely to avoid betrayal of a certain spirit of analysis by eschewing either too slavish or too wild a form of application. This ANT is proposed as "modes of thinking and speaking near ANT, that is, not simply deploying the existing ANT canon of concepts, research strategies and writing experiments, but keeping them near as a source of questions, problems and inspiration" (p. xxii).

To this end, the purpose of the Companion is not to develop a canonical version of contemporary ANT and nor does it aim to provide a collection that is a static snapshot of various members of the family at this point in time. Both those approaches might imply that there is a 'genuine' way to do proper ANT. The ANT inquiries described here go off in many directions, albeit gently harnessed together by the editorial hand. This 'second generation' collection is diverting in the wide range of topics analysed, offering inspiration while main- taining a modest demeanour. It will be welcomed by the large numbers of social scientists who often in their undergraduate studies have been confused by being introduced to a social theory that is not a theory. The essays show how various sorts of situations might be engaged with, rather than explaining either what the steps in using the approach are, or laying the implements out the tool box. The essays on topics drawn from the myriad nooks and crannies of social life by thirtyeight authors, are written in a highly readable, charmingly non-dogmatic English, albeit often slightly idiomatic. The sheer variety of analytic strategies and interpretative forms in the collection reveals the astonishingly wide reach of this way of analytic thinking; ANT can be used to offer telling insight into myriad knotty contemporary socio-cultural issues. The Companion feels for, or even elicits, future directions, and steers towards emergent possibilities.

The ANT that is introduced in the low-key prologue is "an intellectual project that is always in beta: it does not construct edifices... [instead] committing to 'ex-titutionalise' ANT... to cultivate...an open-ended experimental becoming" (p. xxiii). The prologue, a quite adequate account of ANT's institutional 'backstory' will no doubt be useful for several generations of scholars-in-the-making, offering eminently quotable quotes for future undergraduate essays. In preparation for entering the text proper the editors end their introductory narrative in mobi- 
lising the metaphor of 'mapping.' This is a favourite strategy for editors of handbooks and companions, for example, the map and mapping were much in evidence in introduction of the 1995 Handbook of Science and Technology Studies. Although I was surprised by the thought that contemporary ANT is amenable to mapping, so deliciously different were the maps of these two compilations, both in terms of the STS world mapped and the form of the map, that I forgot my hesitation.

The editors deserve a great deal of credit, quite properly their presence is not unobtrusive. They do not lurk in the background pulling strings, their guidance of the project from the beginning being made evident. The generation of the volume's framing, and to some extent individual texts, seem to have been helpfully mediated in initial workshopping. Around two thirds of the contributors are located in European institutions the remaining drawn from all over-an impressive achievement. All contributors are well-placed midcareer academics with disciplinary backgrounds for the most part in anthropology or sociology, yet all are clearly committed to transcending disciplinary boundaries. The fresh younger ANT talent showcased here challenges the old ANT in ways and on topics that likely would never have occurred to the older generation.

The book is divided into six sections, each carefully curated by the editors. Contributions are clustered together into 'families' of between 5 and 7 sibling texts, with vague family likenesses. There are seven short commentaries written in an informative, and consistent editorial voice: an overall introduction, and then six section introductions. Each of the sections is titled by the editors and they suggest that when laid endto-end as books inevitably do, the sequence of sections is "an attempt to chart out the collective journey of ANT so far, and to elicit pointers for new routes ahead... a tour around ANT... concerned with different aspects or facets of ANT's intellectual practices which one would conceivably want to visit, sooner or later, in the process of drawing near to ANT" (p. xxxi).
The essays in section 1 focus on "modes of weaving ANT's conceptual-empirical inquiries... reflecting on problematising, inquiring, comparing, writing, and criticising with or near

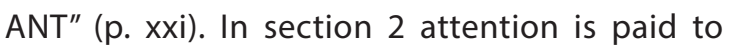
sources of inspiration for ANT, especially silenced, forgotten, or yet to be noticed potential sites of enrichment of ANT studies, in shifting from the past, or unnoticed, in section 3 essays offer soft critique or problematisation of former and current strands of ANT inquiry, and worry at roads not much travelled. Section 4 has authors venturing outside STS to engage with a wide range of knotty puzzles in contemporary collective life, which as things turn out, offer varied conceptual, methodological and ethical challenges for ANT. Section 5 offers new perspectives on scale, an old favourite of the ANT repertoire. The wrapping-up of section 6 showcases some uses of ANT in doing public and professional life: activists who design, designers who consult, and those who run institutions.

So diverse are the topics and voices of the essays, that I found delight and diversion in reading the essays in an orderly way, working my way through a section. But the titles also invite browsing, skipping from one section to another. Many of the individual essays might have found a home in several of these sections. The sections too are discernibly distinct, each has a particular mien or demeanour. The essays in section 1 for example, while diverse seem to be united by a shared ambivalence about ANT ancestors in general, while those in section 2 find common cause in asking what more, or what else, might be drawn from ANT's scholarly roots. Essays in sections 3 and 4 both seem to ask 'But what about...?' with those in 3 focussing on human traits, and 4 on contexts. Section 5, with its focus on scale, asserts solemnly 'This is serious!' while the final group of essays sparkle with exuberance.

I conclude by listing a few more or less random responses to the book.

- The parts are impressive, both the individual texts and their clusters, and yet the whole of this companionable assemblage is still greater than its parts. 
- I came away from the book imagining ANT in a quite different way. As a warren of rabbitholes that readers might choose to fall into or not, but every one of which would unfailingly provide adventure, and where each passage plotted might connect with others, or cheerfully fail to link up.

- I noted that ANT has yet to learn to laugh at itself, perhaps indicating a lingering reluctance to age. Maybe this volume is the beginning of the recognition that nurturing the coming into being of viable successor projects is crucial.
- I wondered what happened to the story of ANT as sociology of semiotically sophisticated translation. To me that still seems to be a useful descriptor of ANT allowing for it as a vague and divergent whole. A friend suggested that translation is actually exactly what this book does.

- I do look forward to ANT learning to take more seriously the work of not taking itself so seriously, it is after-all just another gift of the European Enlightenment albeit that it comes from the Leibnizian end of that remarkably generative time and place. 